\title{
Pain Management During Uterine Artery Embolization for Symptomatic Uterine Fibroids
}

\author{
L. E. Lampmann $\cdot$ P. N. Lohle $\cdot$ A. Smeets $\cdot$ \\ P. F. Boekkooi $\cdot$ H. Vervest $\cdot$ C. M. van Oirschot . \\ R. C. Bremer
}

Received: 29 March 2007/Revised: 29 March 2007 / Accepted: 13 April 2007 / Published online: 29 May 2007

(C) Springer Science+Business Media, LLC 2007

We read with interest the publication in CardioVascular and Interventional Radiology on results from the randomized prospective Emmy trial [1]. The Emmy trial was designed to compare uterine artery embolization (UAE) and hysterectomy as a treatment for symptomatic fibroids. From the beginning in 1995 [2] the knowledge on UAE is increasing and extensive. Most published data and acknowledged information are based on large case series. Nowadays UAE is no longer considered experimental and has definitely found its place in the whole spectra of treatment options for symptomatic uterine fibroids. One of the advantages of UAE is the significantly earlier recovery after the procedure compared to hysterectomy [3].

A structural comparison of individual pain experience between UAE and hysterectomy has never been published in a randomized trial before. Unfortunately, no conclusions can be drawn from the publication by Hehenkamp et al. with regard to pain experience in patients after UAE and hysterectomy, since the study was not designed for this purpose. Many participating centers performed only a few UAEs, without a fixed pain management protocol.

We feel that a fixed and extensive pain management protocol is crucial when performing UAE. At our center,

L. E. Lampmann $(\bowtie) \cdot$ P. N. Lohle · A. Smeets

Department of Radiology, Sint Elisabeth Ziekenhuis Tilburg,

Tilburg, The Netherlands

e-mail: 1.lampmann@wxs.nl

P. F. Boekkooi · H. Vervest · C. M. van Oirschot

Department of Gynaecology, Sint Elisabeth Ziekenhuis Tilburg,

Tilburg, The Netherlands

R. C. Bremer

Department of Anaesthesiology, Sint Elisabeth Ziekenhuis

Tilburg, Tilburg, The Netherlands where we perform an average of 140 UAEs per year, a dedicated pain management protocol is followed. In the Emmy trial, several analgesic approaches have been mentioned such as epidural anesthesia, opiates, nonsteroidal anti-inflammatory drugs (NSAIDs), paracetamol, and combinations. All analgesics used before, during, and after the procedure until discharge were recorded. Three subdivisions in terms of pain management could be extracted: paracetamol and NSAIDs only, opiates and or NSAIDs, and epidural anaesthesia. After discharge most patients were on medication such as paracetamol and/or NSAIDs. Pain after discharge was obviated and patient analgesic use recorded during 6 weeks. As already expected, patients from the hysterectomy arm had significantly higher pain scores during the first 24 hours after treatment. Average pain scores $>5$ during hospitalization occurred in $31 \%$ of the UAE group versus $52 \%$ in the hysterectomy arm $(p=0.012)$. The majority of patients in both groups needed opiates during the first 24 hours as the strongest analgesic option. Consequently, these patients had higher pain scores, except for three individuals in the UAE arm who needed epidural anesthesia because of unbearable pain despite the administration of opiates.

Many protocols have been described for UAE, varying from standard epidural anaesthesia to patient-controlled analgesia (PCA) in combination with NSAIDs and paracetamol [4]. Some authors even advocate performing UAE under general anesthesia [5]. Interpatient variations occur and pain experience as well as pain intensity is unpredictable [6]. No correlations have been detected concerning age, embolization technique, and embolization material size and type (spherical or nonspherical particles), as well as size and/or localization of uterine fibroids, although a clear and significant relation was demonstrated between 
pain and amount of emoblization material utilized (7). Even the effects and role of the psychological status of the patient is difficult to obviate. Hehenkamp et al. conclude that a fixed pain medication protocol cannot be recommended based on their results. They, however, agree that a substantial proportion of patients ends up with high average pain scores, indicating an insufficient pain control.

In our opinion an adequate and extensive pain management protocol for UAE is extremely important, for not only the periprocedural but also the postprocedural period. At our facility we started performing UAE for symptomatic uterine fibroids in 1997. Initially, we encountered many problems with peri- and postprocedural pain management. Our protocol, consisting of $10 \mathrm{mg}$ morphine hydrochloride intramuscularly prior to the procedure and $10 \mathrm{mg}$ morphine hydrochloride four times daily postprocedural, in combination with diclofinac, 100-mg suppository, as well as paracetamol, $1000 \mathrm{mg}$, four times daily, was not adequate to combat the sometimes extensive pain experienced by a considerable amount of patients.

In close cooperation with the Department of Gynaecology and Anaesthesiology we developed an exclusive pain management protocol tailored to UAE (Table 1). This regimen is based on the fact that proper pain management starts prior to the procedure, and not after the first pain experienced by the patient during or just after the procedure itself. At our facility the patient receives an intravenous (IV) drip infusion in the left hand when admitted to the ward. A urine bladder catheter is installed, and, although debateded by many authors, $2 \mathrm{~g}$ kefsol is administered IV 1 hour prior to the procedure. One hour prior to the scheduled UAE procedure the patient is transported to the recovery room and a PCA pump is connected to the IV line loaded with 100 $\mathrm{mg}$ dipidolor and set to a lockout time of 5 minutes. Bolus injections are restricted to $2 \mathrm{mg}$. The patient is carefully instructed on how to operate the pump in case of heavy pain. Just before the procedure the patient is preloaded with a 2$\mathrm{mg}$ bolus injection. During the UAE procedure the patient is carefully monitored by an attending radiographer observing physiological status (pulse oximeter) as well as patient behavior and pain sensations. In most cases the patient will be encouraged by the attending radiographer to operate the button of the PCA pump, resulting in a 2-mg bolus injection, especially when any change in pain level is noticed.

In other words, early prevention of pain is important. After the UAE procedure the patient is transported back to the recovery room and carefully monitored before returning to the ward. The PCA pump is reset to 1-mg bolus injections. In most cases additional diclophenac, 100-mg suppository, and paracetamol, 1000-mg suppository, is needed to keep the pain under control. Accompanying dizziness and nausiness can be treated with zofran, $4 \mathrm{mg}$ IV. In case of insufficient response, $1.25 \mathrm{mg}$ droperidol IV is the next step,
Table 1 Algorithm of UFE pain management

\begin{tabular}{|c|c|}
\hline $\begin{array}{l}\text { Patient } \\
\text { admission }\end{array}$ & IV drip infusion and urine bladder catheter \\
\hline & $\nabla$ \\
\hline Recovery room & $\begin{array}{l}\text { PCA connection and instruction } \\
\text { Dipidolor, 2-mg bolus injection } \\
\text { PCA dipidolor, } 2 \mathrm{mg} / 5 \mathrm{~min} \\
\nabla\end{array}$ \\
\hline $\begin{array}{l}\text { Angiography } \\
\text { suite }\end{array}$ & $\begin{array}{l}\text { Pulse oximeter monitoring } \\
\text { Dipidolor, } 2 \mathrm{mg} \text { IV, during procedure } \\
\text { PCA operation by patient if needed } \\
\nabla\end{array}$ \\
\hline Recovery room & $\begin{array}{l}\text { PCA reset to } 1 \mathrm{mg} \\
\text { Additional: diclophenac, 100-mg suppository } \\
\text { Additional: paracetamol, 1000-mg suppository } \\
\text { Nausea: zofran, } 4 \mathrm{mg} \mathrm{IV} \\
\text { Unbearable pain: } \\
\text { Droperidol, } 1.25 \mathrm{mg} \text { IV ( } 1 \text { or } 2 \times) \\
\text { Dexamethason, } 5 \mathrm{mg} \text { IV } \\
\text { Pain stabilization completed } \\
\nabla\end{array}$ \\
\hline $\begin{array}{l}\text { Re-admission to } \\
\text { ward }\end{array}$ & $\begin{array}{l}\text { PCA overnight } \\
\text { Diclophenac, } 100 \mathrm{mg} / \text { paracetamol, 1000-mg } \\
\quad \text { suppository, } 4 \times \text { daily } \\
\text { Zofran, } 4 \mathrm{mg} \mathrm{IV} \text {, if necessary } \\
\nabla\end{array}$ \\
\hline Next morning & $\begin{array}{l}\text { Removal of PCA, IV drip, and urine bladder } \\
\text { catheter } \\
\text { Diclophenac, } 100 \mathrm{mg} / \text { paracetamol, 1000-mg } \\
\text { suppository, if necessary } \\
\nabla\end{array}$ \\
\hline $\begin{array}{l}\text { Patient } \\
\text { discharge }\end{array}$ & $\begin{array}{l}\text { Diclophenac, 50-mg suppository, } 4 \times \text { daily for } 1 \\
\text { week }\end{array}$ \\
\hline
\end{tabular}

which can be repeated a second time. Last but not least, $5 \mathrm{mg}$ dexamethasone IV may be helpful. When sufficiently stabilized according to pain and nausea, the patient can return to the ward. In most cases after one night of discomfort and pain, PCA can be omitted and the patient mobilized. The urinary bladder catheter is removed and the patient can be discharged, after oral and written instructions.

We strongly believe in this aggressive pain management approach where we try not only to treat the periprocedural pain but also to anticipate any postembolization pain and discomfort.

\section{References}

1. Hehenkamp WJ, Volkers NA, Birnie E, et al. (2006) Pain and return to daily activities after uterine artery embolization and 
hysterectomy in the treatment of symptomatic uterine fibroids: results from the randomized EMMY trial. CardioVasc Intervent Radiol 29:179-187

2. Ravina JH, Herbreteau D, Ciraru-Vigneron N, et al. (1995) Arterial embolisation to treat uterine myomata. Lancet 346:671-672

3. Pinto I, Chimeno P, Romo A, et al. (2003) Uterine fibroids: uterine artery embolization versus abdominal hysterectomy for treatment. A prospective, randomized, and controlled clinical trial. Radiology 226:425-431

4. Zupi E, Pocek M, Dauri M, et al. (2003) Selective uterine artery embolization in the management of uterine myomas. Fertil Steril 79:107-111
5. Brunereau L, Herbreteau D, Gallas S, et al. (2000) Uterine artery embolization in the primary treatment of uterine leiomyomas: technical features and prospective follow-up with clinical and sonographic examinations in 58 patients. AJR 175:1267-1272

6. Carr DB, Goudas LC (1999) Acute pain. Lancet 353:2051-2058

7. Volkers NA, Hehenkamp WJ, Birnie E, et al. (2006) Uterine artery embolization in the treatment of symptomatic uterine fibroid tumors (EMMY trial): periprocedural results and complications. J Vasc Interv Radiol 17(3):471-480 